\title{
A IMPORTÂNCIA DA COMUNICAÇÃO ATLETA-TREINADOR E O PAPEL DO PSICÓLOGO DO ESPORTE
}

\author{
Lorena Madeiral Netto ${ }^{1}$, Rebecca Ravelli ${ }^{1}$, Ilza Ligia Biceglia ${ }^{2}$ \\ ${ }^{1}$ Graduada em Psicologia - UNOESTE. ${ }^{2}$ Psicóloga e docente do Curso de Psicologia - UNOESTE.
}

\section{RESUMO}

O presente artigo apresenta o trabalho referente ao desenvolvimento de uma proposta de intervenção no estágio supervisionado em Psicologia do Esporte no último ano da graduação em Psicologia. Um dos objetivos é investigar e intervir sobre os processos de comunicação interpessoal entre atletas e, entre atletas e treinadores, relativos aos fenômenos psicossociais da dinâmica do esporte em questão e que, podem interferir nas condições psicológicas dos atletas e, consequentemente, no resultado do desempenho e da sua saúde mental. Através da discussão de uma prática aliada à teoria, o trabalho desenvolvido ilustra a avaliação e intervenção em três atletas que buscam o melhor rendimento a partir de queixas de indisciplina, desinteresse e falta de afinco nos treinos apontados pelo treinador.

Palavras-chave: Psicologia do esporte. Relação treinador-atleta; Atuação do psicólogo.

\section{THE IMPORTANCE OF COMMUNICATION BETWEEN COACH-ATHLETE AND THE ROLE OF SPORTS PSYCHOLOGIST}

\begin{abstract}
This article presents the work about the development of an intervention proposal for supervised internship in Sports Psychology in the last year of undergraduate psychology. The objective of work is to investigate and intervene on the processes of interpersonal communication between athletes and between athletes and coaches, for the psychologists phenomenon of the dynamics of the sport in question and that can interfere with psychological condition of athletes and thus results in performance and their mental health. Through discussion of a practice coupled with theory, the work illustrates the assessment and intervention in three athletes seeking the best performance from complaints of indiscipline, disinterest and lack of hard in practice appointed by the coach.
\end{abstract}

Keywords: Sports psychology; Coach-athlete relacion; Psychologist actuation 


\section{INTRODUÇÃO E JUSTIFICATIVA}

A Psicologia do Esporte, compartilhando com Machado (2006), busca em sua ciência a investigação dos processos psíquicos do ser humano frente a prática esportiva, seja ela por lazer ou não. É papel do psicólogo do esporte entender todo o funcionamento do ser humano que possua uma relação com a atividade física, o efeito que essa prática apresenta sobre cada um, para assim intervir sobre aspectos emocionais e psicopatológicos, caso houver necessidade, buscando desenvolver não só a boa performance, mas também a satisfação pessoal, a qualidade de vida, o desenvolvimento socioeducativo e da personalidade por meio da participação no esporte.

Brandão e Valdés Casal (2007) citados por Biceglia (2008, p. 16) defendem a ideia de que na atuação do psicológo do esporte, sob o ponto de vista dos atletas, há a possibilidade de realização de intervenções como o ensino de habilidades psicológicas básicas, que abrange técnicas de relaxamento, concentração, estresse; trabalhos educativos-preventivos e psico-higiene, que visa a orientação de jovens sobre temas específicos como drogas, sexualidade, etc; psicodiagnóstico dos aspectos emocionais que refletem na fisiologia do atleta, de sua personalidade e de seu contexto social e, quando necessário, psicoterapia. Já sob o ponto de vista da equipe multidisciplinar, a intervenção pode ocorrer sob forma de preparação psicológica dos treinadores, possibilitando o autocontrole emocional em situações estressantes; assessoria e consultoria à comissão técnica, auxiliando-os quando necessário; e estruturação de esquemas sobre o tratamento dos problemas técnicos e táticos, quando estiverem relacionados às habilidades psicológicas.

A atuação do Psicólogo do esporte vai ocorrer sempre de acordo com o objetivo formulado por ele, pela equipe técnica de acordo com o contexto onde estiverem inseridos, necessitando antes de qualquer intervenção, avaliar a situação em que se encontram a fim de obter um diagnóstico e planificar o trabalho que será realizado.

Para avaliar e levantar um diagnóstico para uma futura intervenção, Becker e Samulsky (2002, p. 29) apontam alguns instrumentos utilizados pelo psicólogo como: entrevistas, inventários e observações pessoais. Estas técnicas de avaliação permitem obter conhecimento acerca da história pessoal e profissional do atleta, suas emoções antes, durante e após as competições, os objetivos de sua carreira, seu relacionamento com os membros da equipe e com o treinador, avaliar os níveis de estresse por meio de testes psicológicos, atenção, motivação, entre outros fatores.

De acordo com o pensamento de Serpa (2002, p. 20), o treinador é uma figura central, quando o assunto é esporte, já que pode gozar de uma perigosa sensação de poder, onde ele é quem decide, ele modifica comportamentos. Seu papel é de extrema importância, podendo gerar autonomia e criatividade ao seu grupo, mas também pode ser uma figura ameaçadora e limitadora, provocando problemas em sua relação com os atletas. O treinador só conseguirá o rendimento máximo de seus atletas se eles confiarem em seu treinador, acreditarem em sua liderança e captarem o que ele está dizendo, passando para seus ordenados.

A relação treinador-atleta, segundo Renée Vanfraechem-Raway (2002, p. 72) não pode desenvolver-se sem 0 respeito mútuo. 0 treinador deve aprender e conhecer muito bem seus atletas e escutá-los da melhor maneira possível para uma orientação mais eficaz. Sendo assim, o treinador precisa obter um vínculo forte com seu atleta, conhecê-lo a fundo, para assim conseguir extrair deste o seu empenho, sua 
motivação, sua autoestima. Seu conhecimento sobre 0 atleta pode influenciar em sua intervenção, ajudando no controle emocional do atleta.

Grande parte da relação treinador-atleta se estabelece, segundo Becker Jr. (2002), através da comunicação adequada. A comunicação feita de maneira inadequada facilmente gerará conflitos, que gerará, também da comunicação, uma espécie de combate contra - líder e seu trabalho. Para comunicar-se adequadamente, a priori, há a necessidade de entender que cada atleta é diferente, é um indivíduo que possui funcionamento singular e, nas palavras de Becker Jr. (1995 apud BECKER JR., 2002, p. 106) "[...] cada atleta tem uma capacidade diferente dos demais para entender as mensagens". Entender que para cada atleta a comunicação deve ser pautada de forma diferente é o que torna a relação entre treinador e atleta distinta.

Neste sentido, o objetivo deste artigo é discutir sobre a dinâmica da relação entre atletas e treinadore para assim contribuir com as habilidades pessoais deficitárias que prejudicam o desenvolvimento global dos envolvidos. Entendendo a importância da relação entre treinador e atleta positiva, pode-se refletir acerca da contribuição do psicólogo a nível de assessoria e consultoria com treinadores e atletas buscando uma relação de respeito mútuo e comunicação adequada, entendendo a positividade de tal relação frente ao crescimento pessoal do atleta e seu rendimento.

\section{METODOLOGIA}

A metodologia utilizada para levantamento do diagnóstico foi baseada em técnicas de observação, entrevistas, aplicação de testes e inventários com três atletas de uma modalidade esportiva individual e o treinador ${ }^{1}$. Essa metodologia tem como objetivo entender melhor o funcionamento do campo de atuação, do treinador e dos atletas, a dinâmica de relacionamento entre estes, e assim, posteriormente, o levantamento de dados concretos para se pensar em uma futura intervenção.

De acordo com 0 aporte teórico apresentado, pode-se identificar que, durante a fase diagnóstica no local de estágio supracitado, foi percebida a dificuldade de comunicação entre os atletas e a figura do treinador.

Foram utilizadas entrevistas formais e informais com os membros envolvidos, observação dos treinamentos, aplicação de testes psicológicos e inventários a fim de levantar dados relevantes sobre a relação dos membros da equipe, o significado do esporte na vida destes, a relação com o treinador.

\section{ANÁLISES}

Com as observações e entrevistas foi possível notar que a comunicação entre os três atletas e o treinador é extremamente deficitária, o relacionamento entre treinador/atleta é superficial; que os três atletas funcionam muito interligados, atuando de forma explícita contra o treinador, não obedecendo às ordens, atrasando o treino e agindo com indisciplina. $O$ discurso utilizado pelos atletas era o mesmo: o treinador não dá a atenção necessária nos treinos e competições, não os trata de maneira amistosa, nos poucos momentos que participa do treinos dos atletas, ele corrige os erros nos treinos de maneira algoz e nunca os elogia, mesmo que ganhem a competição, relatam que o maior motivo de desmotivação frente ao esporte é a conduta do treinador.

\footnotetext{
${ }^{1}$ Não serão reveladas a cidade, a modalidade e a instituição esportiva referente ao trabalho, para fins de preservação da identidade dos envolvidos que seriam de fácil reconhecimento.
} 
Nas observações pôde-se constatar que os três atletas, principalmente no período em que somente eles treinam, possuem autonomia demasiada, onde o treinador expõe o que tem de ser feito e os deixa sozinhos para execução, e, consequentemente, eles treinam em tom de brincadeira, rindo muito, não efetuando às ordens deixadas pelo mesmo. Enquanto isso, o treinador que somente dita as ordens utiliza o espaço de treinamento, para resolver problemas pessoais, recebendo pessoas, fazendo ligações ou utilizando o computador.

Devemos destacar a falha na comunicação entre os atletas e treinador que, segundo Le Unes \& Nation (1989) citados por Becker Jr. (2002, p. 107), afirmam que a maioria dos treinadores de sucesso são motivadores. Estes contém uma habilidade na fala e na postura que gera desejos de aperfeiçoamento constante no atleta. Para agir de tal modo, saber escutar o que o seu atleta diz e a postura que se tem com cada um em particular é fundamental.

Outra questão relevante na relação é que um dos atletas tem a conviç̧ão que quer seguir a faculdade de medicina, impossibilitando de se dedicar demasiadamente ao esporte, mas, segundo o próprio, falar isso para o treinador seria "não treinar nunca mais", já que este o excluiria dos treinamentos, no sentido de não mais auxiliá-lo enquanto puder ser atleta.

Em relação ao comportamento do treinador, este parece não ter visão do quanto desagrada com sua postura autocrática $e$ distanciada. Tem dificuldade em estabelecer vínculo com seus atletas, por diversas vezes apoiado no discurso de que em sua época, a disciplina na modalidade era a base para um bom atleta, que se deve respeitar e acatar as ordens e nunca questioná-las, o que seus atletas não fazem, justificando que por indisciplina, estes não estão preparados para serem atletas competitivos. Em contrapartida, mesmo observando a conduta indisciplinada de seus atletas, o treinador nunca pontuou, de fato, essa questão, demonstrando mais uma vez a falha na comunicação entre os envolvidos.

A comunicação, ainda compartilhada pelas ideias de Becker Jr. (2002, p. 121), também está associada a forma como o treinador reforça ou puni regras gerais que todo o grupo deve respeitar, baseados nos princípios básicos do reforço (SKINNER, 1968). O reforço por parte do treinador de uma atitude correta do atleta, alimentará este a seguir realizando da mesma forma em outras ocasiões. Já a punição deve ser usada com cautela, para não obter o resultado controverso, como gerar raiva, frustração, medo do fracasso, aumentar as condutas erradas a fim de chamar a atenção do técnico, entre outros. Alguns tipos de punições são retratadas como eficazes, como por exemplo a punição imediata, ocorrendo imediatamente após a conduta inadequada, deixando clara que 0 atleta transgrediu e esta é a punição.

Durante o período de diagnose no local de estágio, algumas mediações foram feitas com os atletas. Os atletas, durante as entrevistas, ficavam exaltados ao relatar os diversos comportamentos de seu treinador, chegando até a gritar uns com os outros para destacar suas indignações nas ações do técnico.

Nestes momentos, a mediação da atuação psicológica era feita no sentido de tentar acolher o relato dos atletas, acalmar os ânimos e colocar um ponto de vista divergente ao que eles sempre relatavam (negativo em relação ao técnico), buscando levantar com os atletas os pontos positivos do treinador e a necessidade de uma atitude frente a falta de comunicação na relação interpessoal, que poderia ser tomada pelos atletas, como forma de agir frente a tanto descontentamento. Essa tarefa não foi fácil de ser realizada e gerou conflitos, deixando os atletas incomodados com algumas visões divergentes 
que foram pontuadas, gerando em uma das atletas um extremo desconforto e resistência, que fez com que esta ficasse algumas semanas sem falar com a estagiária da Psicologia.

Após dois meses do conflito emergido sobre $o$ treinador e a atitude frente a falta de comunicação, os três atletas tomaram a decisão por si só de conversarem com o treinador $\mathrm{e}$ pontuar tudo o que os incomodavam, os descontentamentos, a desmotivação que isso gerava nos treinamentos, a qualidade da relação, enfim, toda a queixa que eles tinham. Neste momento, o treinador também pôde pontuar 0 que pensava sobre os atletas, 0 que 0 desagradava.

Assim, verificou-se a necessidade de uma assessoria psicológica que permita com que os envolvidos na relação esportiva possam: primeiro, ter a oportunidade da expressão emocional; segundo, entrar em contato e identicar os fatores do problema; terceiro, permitir o tempo da elaboração resistencial inerente ao medo e ao desconhecido; e, favorecer o feedback na comunicação interpessoal entre as partes.

A reflexão acerca do dissertado neste artigo é tangenciada sobre como a comunicação deficitária reflete nos atletas e sua percepção no esporte. A comunicação inadequada resultou em um desinteresse geral, onde o treinador enxerga que não tem para quem dar treinos por serem desinteressados, e os atletas vêem o treinador sem vontade de ensiná-los.

Todas as barreiras de comunicação entre eles gerava medo e fantasias em falar com o treinador e sua reação frente ao conteúdo que eles gostariam de falar. Os atletas relataram algumas reações que o técnico poderia ter frente a declarações de interesse dos próprios, e todas as reações imaginadas eram negativas.

\section{CONSIDERAÇÕES FINAIS}

O que se pode concluir é que há necessidade de desenvolver habilidades de comunicação neste ambiente descrito. A atuação do psicólogo do esporte, nesta circunstância, pode ser voltada para a assessoria e consultoria para $\circ$ treinador no desenvolvimento de tais habilidades, possibilitando uma visão mais abrangente de sua comunicação precária e como isto influi nos atletas, para assim construir de fato uma relação eficaz e uma melhor chance de ser ouvido e respeitado, como assim almeja.

A assessoria e consultoria psicológica como método a ser utilizado na intervenção destina-se tanto para o treinador quanto para os atletas, oportunizando um momento de reflexão acerca do vínculo que os membros da equipe possuem, discussão sobre a forma de se comunicar, apontar habilidades que necessitam ser aperfeiçoadas na comunicação com o outro (atleta, comissão técnica, treinador, etc.) entre outros aspectos que podem ser trabalhados, de acordo com a demanda do contexto.

Com os atletas, a intervenção a ser feita, neste sentido, pode ser pensada em um trabalho voltado para a questão da desmistificação do treinador como um "carrasco", que não sabe ouvilos, a busca pela ajuda, demonstração de interesse como forma de motivar o treinador também a ter afinco para treinar estes atletas.

\section{REFERÊNCIAS}

BECKER JUNIOR, B.; SAMULSKY, D. Manual de treinamento psicológico para o esporte. Novo Hamburgo: Feevale, 2002.

BICEGLIA, I. L. Representações Sociais de Profissionais da Educação Física sobre a Psicologia Aplicada ao Esporte. 2008. Dissertação (Mestrado em Educação) Universidade Estadual Paulista UNESP Presidente Prudente.

MACHADO, A. A. Psicologia do esporte: da educação física escolar ao esporte de alto nível. Rio de Janeiro: Guanabara Koogan, 2006. VANFRAECHEM-RAWAY, R. O treinador esportivo, motivador e educador. In: BECKER JR., B. (org.). Psicologia aplicada ao treinador esportivo. Novo Hamburgo: FEEVALE, 2002. 
SAMULSKY, D. Psicologia do esporte:

conceitos e novas perspectivas. São Paulo:

Manole, 2009.

SERPA, S. Treinador e atleta:a relação sagrada.

In: BECKER JR., B. (org.). Psicologia aplicada

ao treinador esportivo. Novo Hamburgo:

FEEVALE, 2002. 